\title{
Probabilistic Income-Maximizing Behavior in Regional Migration: An Empirical Test
}

\author{
Robert I. Weinstein \\ and \\ Richard D. Evans*
}

\section{INTRODUCTION}

An extensive empirical and theoretical literature exists on the determinants of migration behavior. A limitation of these studies, however, is their failure to completely consider the effects of risk on the migration decision. Theoretical work regarding risk and migration has been developed by Todaro (13) and Brennan (1). Their approach emphasized employment uncertainty. The empirical literature has recognized this aspect of risk through the use of unemployment and prospective unemployment variables $(8,1)$.

A recent article by Arthur Silvers extends the theory of migration as a probability process by considering the impact of income risk on migration (12). Silvers points out that most analyses assume that decisions are based

. . . only on wage expectations, ignoring the issue of risk. Risk neutrality has been assumed. Although individuals may well believe a certain region will yield the highest expected return, if this choice entails the possibility of substantial loss, the choice may be downgraded. Such individuals are said to be "risk averse" (12, p.33).

The approach taken by Silvers reformulates the migration decision as an expected utility maximization model in which income variance is an argument in the decision-makers utility function. If decision-makers can be characterized as risk-averters, then Silvers hypothesized that the perception of greater income risk associated with migration to a given region should result in lower migration to that region relative to others $(12$, p.33). This approach is consistent with the human capital model of decision-making under uncertainty developed by Weiss (26), Hause (9), and with models of occupational choice under uncertainty such as that developed by King (10), and Evans and Weinstein (6).

This paper provides an empirical test of the hypothesis that migrants consider income risk in their evaluation of the returns to migration in that higher

\footnotetext{
${ }^{*}$ Dr. Robert I. Weinstein is Associate Professor of Economics and Executive Director of the Institute for Urban Affairs and Business Research at Bradley University, Peoria, Illinois. Dr. Richard D. Evans is Assistant Professor of Economics at Memphis State University, Memphis, Tennessee.
} 
levels of income risk for a given region reduce the rate of net migration into that region. The next section of the paper considers the theoretical approaches to the incorporation of income risk in the migration model and provides a short discussion of limitations. Section three presents the empirical results of the tests of each of the alternative approaches. The final section discusses policy implications of the empirical results and directions for further research.

\section{INCOME RISK AND MIGRATION}

This mean-variance analysis of the risk in migration is subject to all the theoretical difficulties of mean-variance analysis (7). In addition, it must be assumed that general income distributions in a state describe income risk to migrants to that state. Clearly, some migrants know with certainty that they will be employed; perhaps knowing their salary. Others will be unemployed, take entry level positions, and have inferior prospects relative to the general population. Statewide income distributions may be valid as descriptive of long term prospects in the state or as descriptive of aggregate rather than individual opportunities.

The migration model is specified as follows: (1) $M=f\left(X_{k}, \bar{Y}, s\right)$ where for each region and migration group

$$
\begin{aligned}
\mathrm{M}= & \text { net migration rate (as a percentage of the group total population), } \\
\mathrm{X}_{\mathrm{k}}= & \text { " } \mathrm{k} \text { " independent variables capturing the labor market and other } \\
& \begin{array}{l}
\text { characteristics of the region (other than income distribution charac- } \\
\text { teristics), }
\end{array} \\
\overline{\mathrm{Y}}= & \text { the arithematic mean income for all income earners, and } \\
\mathrm{s}= & \text { the standard deviation of income for individuals who earned in- } \\
& \text { come. }
\end{aligned}
$$

This model evaluates the relationship between income risk and net migration. If both in-migrants and out-migrants are risk averse, then relatively higher income risk for a given region should both reduce in-migration and increase out-migration. Thus, income risk is expected to be inversely related to net migration. Higher mean income for a region relative to others should increase net migration. Thus, it is expected that

$$
\begin{aligned}
& \frac{\partial M}{\partial \bar{Y}}>0 \\
& \frac{\partial M}{\partial s}<0
\end{aligned}
$$


A problem emerges in attempts to empirically investigate migration with this model. Theoretically, if in-migrants are risk-averse then the presence of high risk in a given region should induce less in-migration and more outmigration; hence a lower net migration rate. The consequent decline in the amount of available labor should result in a higher equilibrium income in the high risk region relative to lower risk regions. This higher mean income can be described as a compensating differential resulting from the differentials in riskiness among regions. Thus, to the extent that migration does act as an equilibration mechanism one would expect the presence of a positive correlation between mean and standard deviation of income among sample regions. In addition, multicollinearity may emerge because the income distributions for most regions are roughly bounded at the low end. As a region's incomes grow over time, they may grow by adding more incomes to the high income end of the distribution without reducing the number of incomes at the low end. Consequently, the process of economic growth would tend to increase both the mean and standard deviation of income simultaneously creating multicollinearity between these two variables. If significant multicollinearity between these two variables is present, estimates obtained for the impact of $\bar{Y}$ and s on $\mathrm{M}$ would be of reduced reliability perhaps causing them to appear to be statistically insignificant.

If the presence of significant multicollinearity emerges, the combined impact of mean income and income variance might be better captured through the use of a variable that merges these income distributional characteristics into a single measure. One approach suggested by the literature is the use of the coefficient of variation, the ratio of the standard deviation of income to the mean level of income for the region $(\mathrm{s} / \overline{\mathrm{Y}})$. Assuming risk averse behavior, the higher standard deviation per dollar of mean income per region, the less attractive the region would be to potential migrants, consequently the lower the expected net migration rate for the region. The variable $(\mathrm{s} / \overline{\mathrm{Y}})$ is utilized in the next section as a variable describing the impact of risk on the migration decision.

\section{EMPIRICAL RESULTS}

The measures of income risk described in the preceding section are incorporated in a simplified migration model in order to test the null hypothesis that net migration is unaffected by the extent of income risk in alternative locations. The tests are performed on white and nonwhite net migration data for the 48 states.* Definitions of the variables used in the model and the source of data used in their measurement are provided below:

$$
\begin{aligned}
M= & \text { net migration rate (net migration as a percent of } 1960 \text { popula- } \\
& \text { tion), } 1960-1970(17, \text { Table 22) }
\end{aligned}
$$

*Alaska and Hawaii were excluded due to their substantial climatic and distance characteristics. 
$\mathrm{W}=$ average monthly aid per family with dependent children in 1965 (16, Table 29);

$\Delta \mathrm{E}_{50-60}=$ the percentage change in total civilian employment, 1950-1960 (18);

$\mathrm{T}=$ normal monthly average temperature, 1940-1970 (15, Table 295);

$\mathrm{U}=$ the unemployment rate (percentage) in 1960 (14, Table 46);

$\Delta \mathrm{Y}^{\prime}=$ the change in median family income, 1960-1970 (14, Table $65 ; 22$, Table 57 );

$\overline{\mathrm{Y}}=$ mean income of individuals employed during 1960;

$\mathrm{s}=$ standard deviation of income, 1960; and

$\mathrm{s} / \overline{\mathrm{Y}}=$ the coefficient of variation in income, 1960.

Variables $\overline{\mathrm{Y}}, \mathrm{s}$, and $\mathrm{s} \overline{\mathrm{Y}}$ are all computed from data on state income distributions obtained from the 1960 Census of Populations (14). The income distributions used include only individuals who reported earned income. The exclusion of individuals earning zero income is important since the presence of a high proportion of unemployed in a region would be expected to be associated with a high percentage of individuals earning no income. This would result in the introduction of multicollinearity between the unemployment variable and the variables constructed from the income distributions. All of the variables constructed from the state income distributions in addition to variables $\mathrm{M}, \mathrm{U}$, and $\Delta Y^{\prime}$ are measured separately for the two racial groups. The subscripts "w" and " $n$ " indicate the use of race specific data for whites and nonwhites respectively.

The basic migration model used (excluding the variables reflecting the base year income distributions) is relatively simple. It has been constructed to minimize problems of simultaneity $(8,12)$. The coefficient for variable $\mathrm{W}$ (the welfare payments measure) is expected to be positive for nonwhites and negative for whites, reflecting the differential receipt of payments and tax contributions for these two racial groups $(1,3,11) . \Delta \mathrm{E}_{50-60}$ provides a measure of the expected change in employment opportunities over the migration period, and a positive coefficient is expected. The average monthly temperature variable $(\mathrm{t})$, although theoretically expected to be positively related to net migration, has been found in previous studies to be inversely related for the 1960-1970 migration period (3). Rather than indicating preference for colder weather, this result reflects the general flow of migration from south to north over the period. Since the nonwhites flow reflects perceived superior economic and social conditions, whereas, the flow for whites reflects only the economic conditions, the absolute value of the negative coefficient for nonwhites is expected to be larger than that for this temperature variable for whites. 
TABLE 1

Regression Results

Dependent Variable: White Net Migration Rate, 1960-1970

(" $t$ " values in parentheses)

\begin{tabular}{ccccccccccc}
\hline $\begin{array}{c}\text { Adjusted } \\
\mathrm{r}^{2} \\
\text { (f) }\end{array}$ & d.f. & Constant & $\mathrm{W}$ & $\Delta \mathrm{E}_{50-60}$ & $\mathrm{~T}$ & $\mathrm{U}_{\mathrm{w}}$ & $\Delta \mathrm{Y}_{\mathrm{w}}^{\prime}$ & $\overline{\mathrm{Y}}_{\mathrm{w}}$ & $\mathrm{s}_{\mathrm{w}}$ & $(\mathrm{s} / \overline{\mathrm{Y}})_{\mathrm{w}}$ \\
\hline .59 & 41 & -25.20 & -.078 & +.369 & -.228 & +.988 & +.006 & +.004 & & \\
$(12.07)$ & & & $(1.536)$ & $(5.895)$ & $(1.044)$ & $(0.866)$ & $(2.085)$ & $(0.978)$ & & \\
\hline .63 & 41 & +60.21 & -.108 & +.350 & -.215 & +.850 & +.005 & & & -74.63 \\
$(14.41)$ & & & $(2.364)$ & $(6.194)$ & $(1.054)$ & $(6.806)$ & $(2.037)$ & & & $(2.480)$ \\
\hline .66 & 40 & +34.45 & -.078 & +.371 & -.105 & +.964 & +.004 & +.027 & -.049 & \\
$(13.90)$ & & & $(1.688)$ & $(6.521)$ & $(0.517)$ & $(0.930)$ & $(1.578)$ & $(3.246)$ & $(3.102)$ &
\end{tabular}

The unemployment variable is expected to have a negative coefficient. However, numerous studies have found little statistical relationship between net migration and unemployment in the base year (8). In part, this observation may have reflected the problem of multicollinearity discussed above. In any event, race specific values for unemployment were included as a measure of employment risk. Since the extent and variance in unemployment was, over the migration period, quite small for whites, but substantial for nonwhites, the size of the coefficient for " $U$ " is expected to be more significant and larger in absolute value for nonwhites as compared with whites. Finally, following the work of Cebula and Vedder (5) and Premus and Weinstein (11), race specific values for income change $\left(\Delta Y^{\prime}\right)$ are used as measures of income expectations over the migration period. A positive sign is expected for this variable's coefficient for both whites and nonwhites.

The remaining variables provide measures of the attractiveness of the base year income distributions of the states for each racial group. The mean income is expected to have a positive sign in both the white and nonwhite equations.

Tables 1 and 2 present the results of the tests of the hypotheses for white and nonwhite net migration respectively. All equations were statistically signficant as is indicated by the F statistics and explained a substantial amount of the variation in net interstate migration rates for both whites and nonwhites.

The results obtained for the basic migration equation variables were pretty much as expected. With the exception of unemployment among whites in Table 1, the signs for all coefficients were as expected. The positive coefficient for white unemployment, however, was not statistically significant. For nonwhites, however, as expected, the unemployment was negatively related to net migration and the coefficient was found to be more significant when compared to the results for whites for each comparable equation. The temperature variable was found not to be highly statistically significant for the white sample but was far more significant in all equation forms for nonwhites. 
TABLE 2

Regression Results

Dependent Variable: Nonwhite Net Migration Rate, 1960-1970

(" $t$ " values in parentheses)

(6)

\begin{tabular}{ccccccccccc}
\hline $\begin{array}{c}\text { Adjusted } \\
\mathrm{r}^{2} \\
\text { (f) }\end{array}$ & d.f. & Constant & $\mathrm{W}$ & $\Delta \mathrm{E}_{50-60}$ & $\mathrm{~T}$ & $\mathrm{U}_{\mathrm{w}}$ & $\Delta \mathrm{Y}_{\mathrm{n}}^{\prime}$ & $\overline{\mathrm{Y}}_{\mathrm{n}}$ & $\mathrm{s}_{\mathrm{n}}$ & $\left(\mathrm{s} / \overline{\mathrm{Y}}_{\mathrm{n}}\right)$ \\
\hline .71 & 41 & -2.49 & .110 & +.219 & -.805 & -.687 & +.001 & .017 & & \\
$(19.88)$ & & & $(1.523)$ & $(2.623)$ & $(2.252)$ & $(1.530)$ & $(0.964)$ & $(3.302)$ & & \\
\hline .70 & 41 & +100.02 & +.147 & +.260 & -1.035 & -.482 & +.0003 & & & -68.75 \\
$(19.56)$ & & & $(2.243)$ & $(3.205)$ & $(3.076)$ & $(0.990)$ & $(0.173)$ & & & $(3.206)$ \\
\hline 72 & 40 & +17.17 & +.109 & +.240 & -.884 & -.433 & +.0003 & +.029 & -.023 & \\
$(18.03)$ & & & $(1.535)$ & $(2.885)$ & $(2.494)$ & $(0.924)$ & $(0.173)$ & $(3.239)$ & $(1.587)$ & \\
\hline
\end{tabular}

The results for the welfare benefits variable were also consistent with $a$ priori expectations. A negative coefficient for W (significant at the .10 level) was obtained for whites and a positive coefficient (significance varying between approximately the .10 and .01 levels) was obtained for nonwhites. The employment expectation variable, $\Delta \mathrm{E}_{50-60}$, was highly significant for both racial groups. Finally, the income expectations variable was only found to be statistically significant in the white regressions. Two possible explanations might be that information on expected income growth for nonwhites was either generally lacking or not considered by nonwhite migrants because of the rapidly changing socioeconomic conditions experienced by this group.

The introduction of the variables reflecting base year income distributions into the migration model has remarkably little impact on the size of coefficients for $\mathrm{W}, \Delta \mathrm{E}_{50-60}, \mathrm{~T}, \mathrm{U}$, or $\Delta \mathrm{Y}^{\prime}$ or their significance. Equations 3 and 6 show the effects of the use of mean income in the white and nonwhite migration equations respectively. This equation form would be appropriate if migrants were unconcerned with income risk (risk neutral). Therefore, equations 3 and 6 are used as the baselines for whites and nonwhites for comparing the other regression results that incorporate risk characteristics of the state income distributions. Although the coefficient for mean income has the expected sign in both equations, it is only statistically significant in the nonwhite equation.

Equations 5 and 8 show the effects of introducing the standard deviation of income into the regressions for each racial group. In both cases, the coefficients are negative as expected and are statistically significant at the .01 level (indicating an inverse relationship between the extent of income risk and net migration). It should be noted that the introduction of standard deviation of income in the white equation increases the size and significance of the coefficient for mean income. This result reflects the presence of multicollinearity between these two variables. The fact that the coefficient for white mean in- 
come was not significant in equation 3 can also be explained as a reflection of the multicollinearity between mean and standard deviation of income. Since the impact of standard deviation of income on net migration is negative, whereas the impact of mean income is positive, when only mean income is included in the equation, these opposing influences are captured by the single variable resulting in little statistical significance. However, when both mean and standard deviation of income are included, the improved specification results in a more accurate reflection of the impact of mean income on net migration. Although the simple correlation between mean and standard deviation of income is quite high for whites and nonwhites, the multicollinearity is not so severe that the results obtained from their joint inclusion show either variable to be statistically insignificant.

The ratio of the standard deviation of income to the mean of income the coefficient of variation) is introduced in equations 4 and 7 . For both whites and nonwhites, this ratio was statistically significant at the .01 level and was negatively related to net migration. This result is also consistant with the hypothesis that migrants are repelled by income risk in making their location decision. In addition, the use of the coefficient of variation reduces the problem of multicollinearity as described above.

Generally a comparison of the results of the migration models presented in Tables 1 and 2 suggest that income risk does exercise a negative influence on net migration of both whites and nonwhites. The larger coefficients on the income risk variables seen in the white net migration equations are within one and a half standard errors of those for the nonwhite equations. On the basis of all of the results, the null hypothesis that net migration of whites and nonwhites is unaffected by income risk must be rejected.

\section{CONCLUSIONS}

This paper has considered issues involved in the incorporation of income risk into aggregate net migration models. The results of the empirical tests of alternative risk measures indicates support for the hypothesis that the extent of net migration is inversely affected by income risk. Although the overall predictiveness of the migration models was not changed excessively in the case of nonwhites, the incorporation of income risk measures (standard deviation of income in particular) into the white migration model increased the explained variation by as much as 10 percent over the use of mean income alone. Furthermore, the coefficient for mean income was substantially affected.

The results of this analysis, however, cannot be accepted as exhaustive of the work that needs to be done on this issue. Several extensions can be suggested. First, the use of directional flow migration data would be expected to provide a better test of the effects of income risk on migration. Second, income risk characteristics could be included in a more completely specified model that examines migration as part of a simultaneous process that determines employment, income and unemployment change as well. Theoretically, changes in 
the risk characteristics and/or mean income would be expected to emerge from this simultaneous process over the migration period. Third, as more current data becomes available on migration flows, the stability of the results obtained can be analyzed. Although the problem of multicollinearity between mean income and measures of income risk may not have substantially damaged the results of this test for the 1960-1970 period, the problem may prove important for future time periods or for analysis of migration in other countries. Last, if differences in the occupational and industrial structure among alternative locations could be incorporated into the model, the influence of these factors on state income distributions could be controlled.

A partial test of the impact of differences in the industrial structure on the results presented was attempted. The percentage of total employment in agriculture in 1960 was introduced as an independent variable into the model. Separate white and non-white percentages were used in the different racial models. In the cases of non-whites, the results were not significantly affected and the percentage of non-whites employed in agriculture was not found to be statistically significant. To some extent its insignificance could be attributed to intercorrelation of this variable with non-white median income change. In the case of whites, the percentage of whites employed in agriculture was found to be statistically significant in all three models. The inclusion of this variable, however, did not significantly affect either the coefficient or the significance of the critical variables capturing the impact of mean and standard deviation of income on migration. Thus, the results indicating the risk averse behavior of migrants hold even with this model respecification. However, a more disaggregated analysis of the impact of industrial structure might generate significantly different results.

\section{REFERENCES}

1. Brennan, J. J. "A More General Theory of Resource Migration." In Brennan, J. J., (ed.), Patterns of Market Behavior, Providence: Brown University Press, 1965.

2. Blanco, Cicely. "Prospective Unemployment and Interstate Population Movements." Review of Economics and Statistics, May, 1964, pp. 221-222.

3. Cebula, R. M. "Analysis of Net Interstate Migration: Comment." Southern Economic Journal, April, 1975, pp. 290-293.

4. Cebula, R. J., and Vedder, R. K. "A Note on Migration, Economic Opportunity, and the Quality of Life." Journal of Regional Science, Volume 13, No. 2, 1973, pp. 205-211.

5. Cebula, R. J., and Vedder, R. K. "An Emprical Analysis of Income Expectations and Interstate Migration." Review of Regional Studies, Volume 5, No. 1, pp. 19-28.

6. Evans, Richard D., and Weinstein, R. I. "Ranking Occupational Alternatives as Risky
Prospects," Industrial and Labor Relations Review, forthcoming.

7. Feldstein, Martin S. "Mean-Variance Analysis in the Theory of Liquidity Preference and Portfolio Selection." Review of Economic Studies, Vol. XXXVI, No. 1, March, 1969, pp. 5-12.

8. Greenwood, M. L. "Research on Internal Migration in the United States: A Survey." Journal of Economic Literature, 1970, pp. 397-433.

9. Hause, John C. "The Risk Element in Occupational and Education Choices: Comment." Journal of Political Economy, Vol. 82, April, 1974, pp. 803-807.

10. King, Allan. "Occupational Choice, Risk Aversion, and Wealth." Industrial and Labor Relations Review, Vol. 27, No. 4, July, 1974, pp. 586-596.

11. Premus, R., and Weinstein, R. "Nonwhite Migration, Welfare Levels and the Political 
Process: Some Additional Results." The Review of Regional Studies, Vol. 7, No. 1, Spring, 1977, pp. 11-19.

12. Silvers, Arthur L. "Probabilitic Income Maximizing Behavior in Regional Migration." International Regional Science Review, Fall, 1977, pp. 29-40.

13. Todaro, M. P. "A Model of Labor Migration and Urban Unemployment in Less Developed Countries." American Economic Review, March, 1967.

14. U.S. Bureau of the Census. U.S. Census of Population, 1960. General Social and Economic Characteristics, U.S. Summary and Related State Volumes. Washington, D.C.: U.S. G.P.O., 1963.

15. U.S. Census of Population, 1970. General Social and Economic Charac- teristics, U.S. Summary and Related State Volumes. Washington, D.C.: U.S. G.P.O., 1972.

16. Statistical Abstract of the United States, 1966. Washington, D.C.: U.S. G.P.O., 1967.

17. Statistical Abstract of the United States, 1972. Washington, D.C.: U.S. G.P.O., 1973.

18. U.S. Department of Labor. Employment and Earnings, States and Areas, 1939-75. Bulletin 1370-12, Washington, D.C.: U.S. G.P.O., 1977.

19. Weiss, Y. "The Risk Element in Occupational and Educational Choices." Journal of Political Economy, Vol. 80, December, 1972, pp. 1203-13. 